\title{
Study on Cultural Carrier and Characteristics of Folk Custom Landscape in Jinan
}

\author{
Xuefeng Liu \\ Chengdu Agricultural College \\ Chengdu, China
}

\author{
Huili Han \\ Chengdu Agricultural College \\ Chengdu, China
}

\author{
Xiaofang $\mathrm{Yu}$ \\ Sichuan Agricultural University \\ Chengdu, China
}

\begin{abstract}
This paper puts the folk custom landscape as the main object of study, and analyzes and arranges the cultural carrier of folk custom landscape in Jinan, and summarizes that there are three forms of cultural carrier, that is, material cultural carrier, behavior cultural carrier and mental cultural carrier. Finally, this paper summarizes the characteristics of folk custom landscape in Jinan and provides reference for the construction of regional landscape design in Jinan and other cities.
\end{abstract}

Keywords-folk custom landscape; carrier of culture; characteristic

\section{INTRODUCTION}

Folk custom landscape is a new research field which regards folk culture as its main research object and human landscape as its main research carrier, which is a kind of new attempt. Folk custom landscape includes both folk culture and human landscape. Therefore, this paper mainly studies the characteristics of folk custom landscape in Jinan through the study of its cultural carrier to achieve its purpose.

\section{ANALYSIS OF FOLK CUSTOM LANDSCAPE CARRIER IN JINAN}

The research carrier selected by this paper mainly includes material culture carrier (spring culture and architectural landscape culture), behavior culture carrier (culinary culture, folk art, festival custom) and mental culture carrier (religious culture), and this paper summarizes the characteristics of folk custom landscape in Jinan by analyzing and arranging some knowledge systematically.

\section{A. Material Cultural Carrier}

The layer of material culture is the sum of the way of material production activities and products of human beings, which is the cultural thing that is touchable and has the material substance. Of which the spring culture and

This paper is the phased achievement of Analysis of the

Characteristics Construction of City Folk Custom Landscape in Chengdu of academic research project of Chengdu Agricultural College, and project number: cny $13-08$. architectural landscape culture are the main representatives in the folk custom material culture in Jinan.

\section{1) Folk custom and spring culture in Jinan}

Jinan is an ancient cultural city with a long history, also known as the "Spring City". Since ancient times to the present, Jinan has many springs with its unique geographical location. Jinan has four spring areas, ten spring groups and 733 natural springs, of which these spring pools, there are four famous springs which have long enjoyed a good reputation and they are Spouting Spring, Black Tiger Spring, Five Dragon Pool and Pearl Spring (famous springs in Jinan city, Shangdong Province). In addition to these four spring areas, there are countless suburban springs and they are named "Seventy-two Springs". Many springs form the developed river system, and four spring groups and "Seventy-two Springs" moisten the city like the south of the Yangtze River, and "a city of mountains half city lake" becomes her best footnote[1]. The beauty of the rivers and mountains gets the best combination here so that Jinan deserves the reputation "The World Spring City". "Springs and Weep Simon Poplar in every household", the springs of Jinan are a part of ordinary people' life, and are amiable to people and close to nature and all the basic necessities of life can not do without the spring water. The springs of Jinan are unique in the world, and the clear springs create the unique spring culture and these springs are further endowed with profound cultural and humanistic significance. This culture will live forever with the springs and bring new life and vitality to the ancient city of Jinan.

Springs are the unique natural landscape of Jinan. It is a significant carrier of Jinan's profound historical culture and an important part of famous historical and cultural city. It is also a crucial factor in creating a regional urban landscape in Jinan.

2) Folk custom and architectural landscape culture in Jinan

The architectural landscape of Jinan mainly includes residential building, religious building and garden building. Jinan is a famous historical and cultural city. There are over 
200 streets and alleys, more than 600 ancient buildings and traditional dwellings. There are more than 30 old streets and alleys in the city, which are well preserved, such as Furong Street and Jinju alley. There are nearly 100 well preserved ancient buildings, traditional dwellings, modern and contemporary representative buildings and so on[2].

Jinan is located in North China, and the dwellings adopt the northern quadrangle courtyard and a simple courtyard system layout[3]. Jinan's dwellings mostly adopt the local materials, such as the gray brick, Chinese-style tile and so on, and the overall color is gray. The corner adopts white lines to draw up and the window frame uses the dark red color, with the cyan tiles. The overall color of dwellings is quiet and peaceful, which highlights the characteristics of serene and peaceful dwellings and is full of vitality. The components of Jinan's dwellings mainly include bar, screen wall and sculpture. The bar is one of the highlights of Jinan's courtyard, in addition to the principal rooms (in a courtyard, usu. facing south), and the bar is higher than the roof of all other rooms. Its physique is deep, and mould is simple and the size is big and complete, which reflect the characteristics of the northern dwellings. The ridge, block with spear and other detailed parts are handled with beautiful curves. The ridge of scorpion tail shapes tilts, its light stretch of image contrasting with the overall thick and echoing with the cool spring and elegant water lane, which makes the Jinan's quadrangle courtyard with a flavor of south China. The screen wall is the very decorative parts in Jinan's dwellings and mostly combines with gable wall of wing, which is not only attached on gable wall, but also overhangs on the gable wall, and there are many exquisite carved stones. The core of screen wall adopts square brick to joint patterns or to decorate with brick carving patterns. The most highlighted thing that can reflect the characteristics of Jinan is the colorful ridge which tilts highly above the screen wall and echoes the colorful ridge in the bar. Carving art is widely applied in Jinan's dwellings. The exquisite carvings which can be seen everywhere in the courtyard witness that Jinan has a traditional culture with a long history. The bar, screen wall, hall and tiger gate all reveal the folk carving art. Circular engravure is smooth and plentiful, and embossment is like floating clouds and flowing water -- natural and smooth, and openwork carving is dainty and exquisite, which are sedimentary deposits of carving art essence of the generation after generation of Jinan's people for thousands of years. What is particularly noteworthy is that the image of "mud lotus" is very common in the courtyard of Jinan, which is the embodiment of the local characteristics of Jinan. Jinan's dwellings have a kind of rustic scenery in the details of decoration, in addition to the traditional plum, bamboo, magpies, bats and other patterns on the components of gable wall, window and bar, the images of "Hui" type character, "Wan" type character and lotus are also added to the decorations and their types are rich and colorful, which reflects the people's love for the good things and infinite creativity.

Jinan is a pluralistic city and its religious cause is prosperous, especially affected by Catholicism and Buddhism. Therefore, these two kinds of religious buildings are prominent. Among them, the most representative buildings are General Temple Christianity church, Hongjialou Catholic Church and Shengtong Temple. The architectural complex is the earliest modern architectural art masterpiece in Jinan, and the architecture blends Chinese with foreign characteristics and fuses the southern with northern features. Jinan's architecture has obvious regional characteristics, which reflect the architectural features of collision and fusion of Chinese and western cultures in the colonial period.

In the practice of urban landscape construction, Jinan garden inherits and develops a long historical tradition and constantly innovates and improves the level of garden art. Jinan traditional garden sprung up very early and had been recorded in the Spring and Autumn Period. The Baotu Spring Park, the Daming Lake Park and Five Dragon Pool Park are the most representative garden buildings in Jinan. Because of the geographical position, cultural environment, political economy and natural factors and other characteristics, Jinan has concentrated many forms of gardens on itself. In the course of garden's development, garden's shape and structure combines with the characteristics of Jinan's climate, dwellings and so on, which reflects the regional characteristics of Jinan traditional gardens and their important status in the development of Chinese traditional gardens.

Jinan is a famous commercial and cultural city with a long history. After several urban renewal, a number of excellent commercial streets are preserved and transformed, and the more prominent streets are Quancheng road, Furong street and Bande de printemps commercial pedestrian street. The forms of commercial buildings in Jinan rely on the shape and structure of traditional dwellings and their structures and colors are similar to those traditional dwellings.

\section{B. Behavior Culture Carrier}

\section{1) Folk custom and cooking culture in Jinan}

Jinan's cooking culture is closely related to the unique history, culture, geography and climate of Jinan. Jinan's cooking culture is a distinctive and relatively independent subsystem in many Chinese cooking culture circles. Jinan's diet mainly has the following notable characteristics: first, the widespread use of raw material; second, excellent and varied cooking technology; third, the soup dish is a remarkable characteristic in Jinan's dishes; fourth, rich and colorful flavoring means; fifth, Jinan's dishes are affected by the idea that "one does not object to the finest food" of Confucius, which have sophisticated production and put emphasis on knife skills, heat control and seasoning and have strict requirements for the color, aroma, flavor and form; sixth, in addition to formal dishes, Jinan has a variety of local snacks and these snacks have rich styles, sophisticated production and different flavors; seventh, Jinan also has unique diet customs. Jinan's cooking culture has rich contents and broad development potential, as long as the innovation is expedient, according to the scientific market operation principle, Jinan's cooking culture will certainly 
show extraordinary talents in the development and utilization of modern tourism economy and cultural industry economy.

\section{2) Folk art in Jinan}

Folk art is an unsophisticated and exquisite living fossil in human civilization[4]. Jinan has rich and colorful folk arts, such as microscopic carvings, dough modeling, sculpture porcelain, Lu embroidery, black pottery, gourd sculpture, Tang Jincai, Jiang Gushi, clay sculpture and Chinese knot and so on, however, the most representative is the Shandong clapper ballad, Shanghe drum yangko and Lu embroidery.

Shandong clapper ballad is a kind of Chinese folk art form which derives from Linqing, Jining, Heze, Yanzhou areas of Shandong. The singer hits the board in a quick tempo to narrate and sing with a bamboo clapper or two copperplates in his hands. The age for clapper ballad that has not yet been recorded accurately. Shandong clapper ballad is a kind of entertainment activities for farmers at first, and then it performs in a way of "roadside performances" in the rural town temple fair and gradually becomes mature. These large docks like Linqing and Jining not only bring up the performers of Shandong clapper ballad and provide them with survival condition, but also lead to the mutual learning and competition in different kinds of art forms, which promotes the prosperity and development of the Shandong clapper ballad.

The so-called yangko is a general term for folk songs and dances, but the yangko puts emphasis on dances. At the beginning, the drum yangko derives form Shanghe county of Jinan and has more than one thousand years of history. Yangko is an art form that the farmers dance and sing to celebrate the good harvest and is a kind of folk custom activity that most of farmers celebrate the good harvest and enjoy the spring festival. Drum yangko is formed by wushudance to temper the military organization types, and the dance formation changes constantly and has a style of rough and bold soldiers and invincible hero momentum.

There are many Chinese folk industrial arts and intangible cultural heritages in Shangdong province, and Lu embroidery is one of them. Lu embroidery is the earliest embroidery categories recorded in the historical document and belongs to one of the "Eight Famous Embroidery" [5]. The embroidery threads used by Lu embroidery are mostly the bold twisting silk thread of double strand, commonly known as "clothing line", so it is also called "clothing line embroidery". It has been popular in Shandong, Hebei, Henan and other places, and its embroidery not only has clothing supplies, but also has ornamental painting and calligraphy art. The styles of Lu embroidery are different from other embroideries and adopt chromatic strong twisting double clothing line as its embroidery thread, with floral fabric as substrate. Lu embroidery adopts Qi needle, Chan needle, Dazhi, kingpin, Douhe needle, Zhen embroidery (pigtail gu needle), Jie needle and other stitches, and selects the contents of characters, mandarin duck, butterfly and Furong flower that people love to see and hear, and the lotus are the rare theme. The products of Lu embroidery are varied. The pure handmade Lu embroidery (Jinan silk embroidery) is the intangible cultural heritage determined by Shandong province's government and is the unique high-grade art in Jinan. It is also an ancient and unique local embroidery type, which is different with other embroideries, and is the most representative work in Lu embroidery.

\section{3) Festival custom of Jinan}

Such a famous historic and cultural city, as Jinan, has formed its unique local festivals, for instances: Mount Qianfo Temple Fair, Baotu Spring Lantern Festival and Daming Lake Floating Lanterns and so on.

Temple fair is also known as "fair" or "festival temple fair". Temple fair customs are closely related to the religious activities of Buddhist monasteries and Taoist temples, since they are developed, perfected and popularized with folk religious activities. On September Ninth by lunar calendar of every year, Double Ninth Festival, people will climb Mount Qianfo and stand on the "Shangju Rock" to admire the beauty of chrysanthemum. Since Yuan Dynasty, September the Ninth has been determined as the day of holding Mount Qianfo Temple Fair, when more than 1,000 fixed and running booths on the both sides of one-kilometer mountain road from the foot of the hill to the hillside Xingguo Temple manage articles of daily use, local specialties, local flavour snack and handicraft articles, etc.; moreover, folk arts groups inside and outside the province perform acrobatics, circus, song and dance, etc., hustle and bustle. Mount Qianfo Temple Fair is a model of Double Ninth Festival, so going the fair allows experiencing the traditional customs of Double Ninth Festival. The temple fair has become the pride of Jinan, as the space and storage of communications between traditional and contemporary culture.

January the Fifteenth by lunar calendar is well-known as "Lantern Festival". In Jinan, the annual Lantern has an extremely spectacular scene; especially the Spouting Spring Lantern Festival, with even more unique characteristics. There are full of flower lights, birds and beasts lights, revolving scenic lanterns, story lights, riddle lamps... some are gorgeous and splendid; some plain and elegant; some ingenious and novel, all of which are full with local colors. On that day, eating sweet dumplings is popular in every family. Besides, before and after the Lantern Festival, all the streets and lanes of Jinan are filled with the stilted, the land boat dancers, dragon lantern dancers and lion dancers, etc. People integrate some myths and legends, historical stories and strong love and hate and good wishes into this folk art rich in folk tradition, to increase the cheerful atmosphere of the festival.

In Jinan, at every night of July 30, all the Buddhist temples will hold Obon Festival to say Mass for the departed souls and teach the Buddhist scriptures. Some will burn large quantities of joss-sticks and insert them into ground along the foot of temple walls and walkways to express their piety to the Ksitigarbha; some release souls of the deceased from purgatory by floating river lanterns. Those river lanterns are made of wet flour; after drying, to put soya-bean oil in the light cup, twine cotton into the lampwick and put them in a river after igniting allows them to go downstream. Then, glittering lights paving the entire river like stars are waving to shine the water into admirably red. Today floating river 
lanterns in the Daming Lake has become a part of folk culture, and no longer the inheritance in the traditional sense.

\section{Carrier of Mental Culture}

The mental cultural carriers of Jinan folk landscape are mainly embodied in religious beliefs. Jinan with thousands of years of history has accumulated a wealth of religious and cultural resources. The cultural diversity of Jinan enables different religious beliefs to coexist harmoniously here, including Islamic culture represented by South Mosque, North Mosque and Women's Mosque; Buddhist culture represented by Mount Qianfo Xingguo Temple, Changqing Lingyan Temple, Mount Cuiping Baofeng Temple, Shentong Temple, Shengshui Temple, Xinglong Temple and Lingjiu Temple, etc.; Catholicism culture represented by Hongjialou Church, Pingyin Huzhuang Catholic Church, Chenjialou Catholic Church and Jiangjunmiao Street Catholic Church; Christian culture represented by Jingsi Road Church, Houzaimen Church, Shangshan South Street Church, Yuzhongli Church, Guanzhaying Church, Sanlizhuang Church, Weidong Church; in addition to Taoist culture represented by Beiji Pavilion and Penglai Abbey. Multiple religious cultures coexist in Jinan harmoniously and bring out the best in one another.

\section{FOLK LANDSCAPE CHARACTERISTICS OF JINAN}

Through sorting out the cultural carriers of Jinan folk landscape, the characteristics of Jinan folk landscape are summarized as below:

1. The formation of Jinan folk landscape characteristics is closely related to the changes of Jinan city. In the development and changes for thousands of years, the traditional culture \& folk-custom, and folk-custom \& landscape have been interacting and interpenetrating, which endows Jinan folk landscape with strong regional characteristics, mainly embodied in the cultural carriers of folk landscape.

2. Spring culture is one of the characteristics of Jinan folk landscape in various fields of cultural heritage. Jinan is built by springs and inextricably linked with springs. Jinan spring water permeates into Jinan folk customs; either gardens or buildings are closely bound to water. Spring water gives this Spring City cultural nourishment and aesthetic pleasure, and becomes the cultural deposits continuously flowing in the city culture. Spring culture not only adds the beauty of Jinan and the rhyme of humanities naturally, but manifests the spirits of this plain and ancient city with its wisdom, philosophy and aesthetic value.

3. The cultural carriers of Jinan folk landscape include: spring culture, religious culture, culinary culture, folk art and festival custom, due to historical changes and the impact of modern urban development, whose characteristics are difficult to generalize. Among them, the cultural carrier architectural landscape has clearer features and can become one of the characteristic elements of Jinan folk landscape. Its characteristics are mainly manifested in the following aspects:
(1) Residential architecture: Quadrangle courtyards play a decisive role in Jinan's traditional residential buildings, and its dignified and light arch modeling and wonderful residential sculpture are the characteristics of traditional Jinan dwellings. The old courtyards have the advantages of both the northern and southern courtyards, as it were; that is, it not only possesses the preciseness and dignity of the northern courtyards, but contains the delicacy and beauty of the water town in southern Yangtze River. From the architectural style, greatly influenced by the Western-style buildings in commercial ports in modern times, the circumstance that Jinan traditional residences, western buildings and Chinese \& Western integrative buildings, in a coordinative and harmonious coexistence, concurrently appear in the old cities and sections of Jinan.

(2) Religious architecture: Jinan is a multicultural city where religious career thrives, especially the Catholic and Buddhist with the largest influence, accordingly leaving the most religious buildings. Jinan's urban culture has been fused with religious culture as an organic part.; and one of the most representatives are the Jiangjunmiao Catholic Church, Hongjialou Catholic Church and Shentong Temple. Jinan religious buildings integrate both Chinese and Western culture, both the northern and southern styles, with distinct regional characteristics, reflecting the architectural features of the old Jinan in the colonial period when Chinese and Western culture are involved in a great shock and blend.

(3) Garden architecture: In the practice of urban landscape construction, Jinan gardens inherit and carry forward a long history of tradition; additionally improve the level of garden art by constant innovation. Combining both styles of the North and South, Jinan gardens not only possess the magnificence of the northern gardens, but contains the soul and charm of the South gardens. Jinan enjoys widespread renown as a spring city. As praised by the Song Dynasty essayist Zeng Gong, that "Qi (Old name of Jinan) is abundant in springs which are the best in the world", and according to the late Ming Dynasty poet Wang Xiangchun, "All over the world, there is no such a place except Jinan where water flows outward." Therefore, spring gardens have become the most characteristic of Jinan gardens.

(4) Business street architecture: Jinan has always been a commercial developed city. Quancheng Road, Furong Street and Quanlefang Pedestrian Mall are the epitome on traditional commercial street buildings in Jinan. Jinan's commercial landscape, prominent in the colonial image, includes both the shape and feature of traditional residence quadrangle courtyards and the function and practicability of Western architecture.

\section{CONCLUSION}

Folk landscape is a new research field in the contemporary landscape design and a breakthrough to create region-characteristic urban landscapes, and can be refined and concluded as important design elements. Folk landscape varies to different cities and the design workers should be good at extracting and utilizing the symbols of elements valuable to landscape design. This paper, taking Jinan City 
as an example, straightens out and analyzes the cultural carriers of its folk landscape and summarizes the characteristics of Jinan folk landscape, and provides reference for the construction of regional landscape design in Jinan and other cities.

\section{REFERENCES}

[1] Wang Xiaoming. The World Best Spouting Spring[J]. Openings, 2010.9 (47-48)

[2] Liu Delong. Culture of Qi and Lu and Shandong Folk Custom[J]. Journey of Shandong College of Arts, 2011.6 (4)

[3] Zhu Xiaolin, Liang Ming. Investigation on Modern Dwellings around Jinan Furong Street[J]. Science \& Technology Information, 2010.17 (167)

[4] Hu Huilin. Introduction to Cultural Industries.[M]. Yunnan: Yunnan University Press, 2005.8 (196-203)

[5] Liu Xiaolin. Countermeasure Study on the Development of Ancient City Folk Tourism in Jinan[J]. Journey of Shandong Institute of Commerce and Technology, 2011.4 (1-3) 